\title{
COLORECTAL CANCER IN INDIA: AN ICEBERG ANALYSIS FROM NORTH INDIA
}

\author{
Vikram Narang1, Namrata Puri' ${ }^{2}$, Aminder Singh ${ }^{3}$, Neena Sood ${ }^{4}$, Vineeta Malhotra ${ }^{5}$
}

${ }^{1}$ Assistant Professor, Department of Pathology, Dayanand Medical College and Hospital, Ludhiana.

2Junior Resident, Department of Pathology, Dayanand Medical College and Hospital, Ludhiana.

${ }^{3}$ Assistant Professor, Department of Pathology, Dayanand Medical College and Hospital, Ludhiana.

${ }^{4}$ Professor and HOD, Department of Pathology, Dayanand Medical College and Hospital, Ludhiana.

${ }^{5}$ Ex-Professor and HOD, Department of Pathology, Dayanand Medical College and Hospital, Ludhiana.

\section{ABSTRACT}

Colon and rectal cancers share many environmental risk factors and are both found in individuals with specific genetic syndromes. Carcinomas are rare before the age of 40 years except in individuals with genetic predisposition or predisposing conditions such as chronic inflammatory bowel disease. The incidence is increasing in Indian scenario, therefore there is need to study the disease behaviour, presentations and prognostic factors.

\section{AIMS}

To analyse various histological parameters of colorectal carcinoma and to correlate these parameters with each other and with Ki-67 wherever available.

\section{MATERIAL AND METHODS}

A total of 200 colectomy done for colorectal carcinoma and received in the Department of Pathology, Dayanand Medical College and Hospital during 4-year period were analysed with reference to Histological subtype, grade, stage and correlated these parameters and with Ki-67 wherever available.

\section{RESULTS}

Mean age of presentation of patients with colon carcinoma was $54.2 \pm 14.2$ years with male female ratio being 1.8:1. Rectosigmoid colon was the commonest site of tumor followed by caecum. Adenocarcinoma NOS with moderate differentiation was the commonest histological subtype. Most common T, N and M stage of presentation was T3, N0 and M0 respectively. Features associated with higher stage were young age, male sex, left sided tumors, signet ring cell \& mucinous subtypes, higher grade, infiltrative tumor margins, no lymphocytic response at the advancing edges. MIB 1 labelling index was higher in Stage II patients.

\section{CONCLUSION}

Colorectal carcinomas are less common in Indian population however the incidence is increasing. Therefore the pathologist and clinicians must be aware of precursor lesions and prognostic factors to diagnose and treat the colorectal carcinomas at early stage.

\section{KEYWORDS}

Colorectal Cancer, Grading, Staging, MIB1 Labelling Index, Associated Lesions Colorectal.

HOW TO CITE THIS ARTICLE: Narang V, Puri N, Singh A, et al. Colorectal cancer in India: an iceberg analysis from North India. J Evolution Med Dent Sci 2016;5(3):215-220, DOI: 10.14260/jemds/2016/46

\section{INTRODUCTION}

Colorectal cancer is the fourth most common incident cancer and the second most common cause of cancer death in the United States. Colon and rectal cancers share many environmental risk factors and with specific genetic syndromes; however, there are some differences in etiology. Incidence rates vary approximately 20 -fold around the world, with the highest rates seen in the developed world and the lowest in India. Colorectal carcinomas exhibit variable presentations and associations with environmental and genetic factors and wide variety of precursor's lesions.

Financial or Other, Competing Interest: None.

Submission 15-12-2015, Peer Review 19-12-2015,

Acceptance 07-01-2016, Published 11-01-2016.

Corresponding Author:

Dr. Vikram Narang,

Assistant Professor,

Department of Pathology,

DMCH, Ludhiana.

E-mail: drvikramnarang@yahoo.com

DOI:10.14260/jemds/2016/46
The prognosis depends upon tumor type, grade, stage and MIB1 proliferation index. It has been proposed that tumors with a high proliferative activity more likely to respond to radiotherapy and chemotherapy, especially using those agents, such as 5-fluorouracil, which inhibit DNA synthesis. ${ }^{[1,2]}$ The present study was undertaken to analyse the various Histological parameters of colorectal carcinoma assess Ki-67 Proliferation Index (PI) of colorectal carcinoma and correlate it with various histological parameters.

\section{MATERIAL AND METHODS}

The present four year descriptive study was done in the Department of Pathology, Dayanand Medical College and Hospital during which all the colectomies done for colorectal carcinoma were analysed with reference to light microscopic findings with special emphasis on histological subtypes classified on the basis of "WHO Histological Classification," grade and stage according to "TNM Staging System" and correlated these parameters with each other and with Ki-67 proliferative index wherever available. In each patient the clinical findings (Age, sex and site of tumor) were obtained 
from the medical records. Pathological findings including gross and microscopic features were analysed in detail. Gross features included size and appearance of tumor, features of adjacent colon, presence or absence of perforation and number of lymph nodes recovered. Microscopic features were obtained by examination of Haematoxylin and eosin-stained slides and from information from pathology reports. Features which were noted include histological subtype, grade, depth of invasion, type of tumor margins, lymphocytic response. Presence or absence of lymphatic, vascular or perineural invasion and status of lymph nodes and adjacent colon. Two histopathologists performed an initial review of all the cases and one histopathologist performed the final review. Finally MIB-1 was calculated wherever available and reported it as percentage. The ethical clearance for the study was obtained from the Institutes' Ethics Committee. Statistical analysis was not required as this was a descriptive analysis of the data.

\section{RESULTS}

A total number of 200 cases were analysed in study period. Majority of the patients $(68 \%)$ of colorectal carcinoma encountered in study were of age between 41-70 years with mean age of presentation being $54.2 \pm 14.2$ years; $20 \%$ of the patients were less than 40 years whereas $80 \%$ were older than 40 years. Slight male preponderance was noted with M:F ratio 1.8:1. Majority of patients underwent left hemicolectomy (53\%) and common location of the tumors was rectum comprising 65 cases (32.5\%) followed by caecum 51 cases $(25.5 \%)$. There was only single case of familial adenomatous polyp in which multiple polyps were present along the entire length of the colon with evidence of carcinoma at multiple sites. Majority of the tumors encountered in the study presented as mass lesions to the tune of $49.5 \%$ while infiltrative and ulcerating lesions were present in $25.9 \%$ and $25 \%$ respectively. Histologically, adenocarcinoma NOS formed the major bulk of the study to the tune of $84.5 \%$ of all cases followed by mucinous carcinoma (13.5\%), signet ring cell carcinoma (1.5\%) and spindle cell carcinoma (0.5\%).

T3 was the common tumor stage with 129 cases (64.5\%), i.e. tumor has invaded up to subserosa. The other $\mathrm{T}$ stages of presentation were $\mathrm{T} 4, \mathrm{~T} 1$ and $\mathrm{T} 2$ with $25.5 \%, 2.5 \%$ and $7.5 \%$ cases respectively. Overall, $48.5 \%$ cases had no lymph node metastasis, i.e. N0, whereas $27.2 \%$ were having metastasis in $</=3$ lymph nodes (N1) and in $24.3 \%$ cases metastasis were present in $>3$ lymph nodes (N2). Majority of the patients (52.1\%) of adenocarcinoma NOS had no nodal metastasis (N0). The most common nodal stage for Mucinous carcinoma was N2 (Metastasis in $>3$ lymph nodes). Both signet ring cell carcinoma and spindle cell carcinoma were N2 in $100 \%$ of their cases; $11.1 \%$ cases of Mucinous carcinoma were presented with metastasis at the time of diagnosis whereas only $4.7 \%$ cases of Adenocarcinoma NOS had evidence of metastasis. None of the cases of signet ring cell carcinoma and spindle cell carcinoma encountered in the study were having metastasis at the time of presentation.

It was observed that $80 \%$ of well differentiated tumors had stage II, whereas majority of moderate and poorly differentiated tumors ( $46.3 \%$ and $57.1 \%$, respectively) were of stage III.

Well and moderately differentiated tumors had 1 and 7 cases respectively of stage IV. (TABLE I).
In the present study, 5 cases were associated with Inflammatory Bowel disease, all of them were ulcerative colitis, out of which, and 3 were associated with Adenocarcinoma NOS and 2 with mucinous carcinoma.

There was a single case of poorly differentiated Adenocarcinoma NOS, which was associated with familial adenomatous polyposis syndrome in which the whole length of colon was studded with multiple polyps (>1000). Morphologically, they were Tubular, Tubulovillous or Villous adenomas. Regarding polyp association, it was seen that 19 cases were associated with polyps. Out of which majority were adenomas (17 cases). Tubular adenoma was the commonest association ( 7 cases) followed by Tubulovillous adenoma ( 6 cases) and finally the villous adenoma (4 cases). In one case of mucinous carcinoma there were two polyps, one was Tubular while other were Villous Adenoma. There was one case each of Retention polyp and Peutz Jegher polyp. (TABLE II).

There were few uncommon incidental findings which were associated with various colorectal carcinomas, which included Ischemic colitis (4 cases) in the adjacent colon, foreign body granulomatous response to the mucin ( 2 cases) either in the adjacent colon or in the metastatic lymph node, mucocele of appendix (one case) and granulomas with Langhan's giant cell reaction and caseation necrosis in regional lymph node (One case), submucosal Lipoma (One case), malignant carcinoid tumor (One case).MIB 1 was done only in 18 out of 200 cases. MIB 1 range varied from 2-85 with Mean \pm SD of $36.9 \pm 29.8$. Maximum number of MIB 1 available was of stage II (15) with 9 cases having value $<40$ and 6 with value $>40$. In stage I, MIB- 1 was available for only 2 cases both having value of $<40$. Similar was true for single case of stage IV. (TABLE III).

\begin{tabular}{|c|c|c|c|c|}
\hline & \multicolumn{4}{|c|}{ Stage } \\
\hline & I & II & III & IV \\
\hline \multicolumn{5}{|l|}{ Grade } \\
\hline $\begin{array}{l}\text { Well differentiated } \\
(\mathrm{n}=15)\end{array}$ & $1(6.7 \%)$ & $12(80.0 \%)$ & $1(6.7 \%)$ & $1(6.6 \%)$ \\
\hline $\begin{array}{c}\text { Moderately } \\
\text { differentiated }(n=147)\end{array}$ & $10(6.8 \%)$ & $62(42.2 \%)$ & $68(46.3 \%)$ & $7(4.8 \%)$ \\
\hline $\begin{array}{l}\text { Poor differentiated } \\
(\mathrm{n}=7)\end{array}$ & 0 & $3(42.9 \%)$ & $4(57.1 \%)$ & 0 \\
\hline \multicolumn{5}{|l|}{ Tumor margins } \\
\hline Infiltrative $(\mathrm{n}=173)$ & $3(1.7 \%)$ & $71(41 \%)$ & $88(50.9 \%)$ & $11(6.4 \%)$ \\
\hline Regular $(\mathrm{n}=27)$ & $9(33.3 \%)$ & $13(48.1 \%)$ & $5(18.5 \%)$ & - \\
\hline \multicolumn{5}{|l|}{$\begin{array}{l}\text { Lymphocytic } \\
\text { response }\end{array}$} \\
\hline Nil $(n=25)$ & $1(4.0 \%)$ & $10(40.0 \%)$ & $12(48.0 \%)$ & $2(8.0 \%)$ \\
\hline Mild ( $n=108)$ & $4(3.7 \%)$ & $42(38.9 \%)$ & $56(51.9 \%)$ & $6(5.6 \%)$ \\
\hline Moderate $(n=52)$ & $5(9.6 \%)$ & $25(48.1 \%)$ & $20(38.5 \%)$ & $2(3.8 \%)$ \\
\hline Prominent $(n=15)$ & $2(13.3 \%)$ & $7(46.7 \%)$ & $5(33.3 \%)$ & $1(6.7 \%)$ \\
\hline Table & $\begin{array}{l}\text { istribution } \\
\text { Ictors in } V \text { c }\end{array}$ & $\begin{array}{l}\text { ases in Vari } \\
\text { us Stage Gro }\end{array}$ & $\begin{array}{l}\text { Prognostic } \\
\text { ings }\end{array}$ & \\
\hline
\end{tabular}

\begin{tabular}{|c|c|}
\hline Associated Diseases & No. of Cases \\
\hline Inflammatory Bowel Disease & 5 \\
\hline Polyps & 7 \\
\hline Tubular adenoma & 4 \\
\hline Villous adenoma & 6 \\
\hline Tubulovillous adenoma & 1 \\
\hline Multiple polyps (FAP) & 1 \\
\hline Peutz-Jegher polyp & 1 \\
\hline Retention polyp & Table II: Distribution of Cases according \\
to Associated Diseases
\end{tabular}




\begin{tabular}{|c|c|c|c|}
\hline \multirow{2}{*}{ Stage } & \multicolumn{2}{|c|}{ MIB-1 } & \multirow{2}{*}{ Total } \\
\cline { 2 - 4 } & $<=40$ & $>40$ & \\
\hline I & 2 & 0 & 2 \\
\hline II & 9 & 6 & 15 \\
\hline III & - & - & - \\
\hline IV & 1 & & 1 \\
\hline \multicolumn{2}{|c|}{ Table III: Distribution of MIB-1 in Various Stages } \\
\hline
\end{tabular}

Comparison of Stage distribution in various studies including present one

\begin{tabular}{|c|c|c|c|c|c|}
\hline Stage & $\begin{array}{c}\text { Fisher } \\
\text { et al.[30] }\end{array}$ & $\begin{array}{c}\text { O'Connell }_{\text {'. }} \\
\text { et al.[31] }\end{array}$ & $\begin{array}{c}\text { Salminen } \\
\text { et al.[32] }\end{array}$ & $\begin{array}{c}\text { Fazeli } \\
\text { et al..[33] }\end{array}$ & $\begin{array}{c}\text { Present } \\
\text { study }\end{array}$ \\
\hline I & $25.6 \%$ & $15.1 \%$ & $17.8 \%$ & $8.2 \%$ & $6 \%$ \\
\hline II & $25.1 \%$ & $35.6 \%$ & $58.2 \%$ & $48.1 \%$ & $42 \%$ \\
\hline III & $47.7 \%$ & $27.8 \%$ & $17.1 \%$ & $33.4 \%$ & $46.5 \%$ \\
\hline IV & $1.6 \%$ & $21.5 \%$ & $6.9 \%$ & $10.3 \%$ & $5.5 \%$ \\
\hline
\end{tabular}

\section{DISCUSSION}

Colorectal carcinoma is one of the most common types of cancer in Western countries and is consistently ranked among the top 3 causes of cancer-related deaths. Incidence of rectal cancers is higher in Indian population. ${ }^{[3]}$ The pathologist's assessment of tumor stage and other stage-independent morphologic features, such as vascular/lymphatic invasion, influences treatment strategies for the individual patient. Although the pathologist influences clinical care in colorectal cancer, certain aspects of staging and evaluation of prognostic factors remain challenging and confusing. Of the total 200 cases analysed with mean age of presentation was $54.2 \pm 14.2$ years.

The youngest patient was a 23-year-old female, whereas the oldest was a 90-year male. These figures are in concordance with the studies done by Amin et al.[4] in which the mean age was $54.8 \pm 14.5$ and 63.5 years respectively. Gender proportion was more in favour of males irrespective of the age groups and tumor subtype with Male:Female ratio being 1.8:1. This correlated with the studies done by Krasna et al. and Shepherd et al.[5,6] with Male:Female ratio of 1.8:1 and 1.3:1 respectively. As regards the site of tumors i.e. left versus right side, it was found that $57 \%$ of tumors were present in the left colon and $42.5 \%$ were in right side. Right colon included caecum, ascending colon, hepatic flexure and proximal portion of transverse colon. In studies of Wu et al. and Gomez et al.[7,8] the distribution of carcinoma in Right and Left colon was 32\% and $68 \%$ respectively. The most common subsite to be affected by carcinoma was Rectosigmoid region (45\%).

Rest of the cases were distributed as follows: Caecum (25.5\%), ascending colon (10\%), Transverse colon including flexures (13\%) and descending colon (6\%). Ponz de Leon et al. and Yoshida et al.[9,10] studied distribution of colorectal carcinoma in various subsites and found that the majority of the cases were present in rectosigmoid region (59\%). The second common site of tumor was caecum (25.5\%). In contrast, in the population based studies of Ponz de Leon et al. and Yoshida et al.[9,10] caecal involvement was present only in $8 \%$ of the cases. This discordance can be explained by a recent study done by Fenoglio.[11] et al. who compared the proportion of proximal lesions in the period 1997-2001 and in the period 2002-2006. They found that the incidence of proximal colorectal carcinoma had increased from 25.9\% (1997-2001) to $30 \%(2002-2006)$ and suggested that this proximal shift may be attributed to environmental factors like change in dietary habits or due to improvement in screening procedures.
Also Demers et al.[12] reported that contact time of fecal stream was higher in proximal colon as compared to distal colon due to slower fecal transit time, which may also be responsible for increasing colon carcinoma cases in proximal colon.

Majority of the cases of Adenocarcinoma NOS in the present study were of moderate grade (87\%), well and poorly differentiated tumors constituted $8.9 \%$ and $4.2 \%$ respectively. This is corroborated with studies of Ueno et al., Nabi et al. and Yoshida et al.[10,13,14] all of whom stated that moderate grade is the commonest grade amongst Adenocarcinoma NOS constituting 51\%, 58\% 60\% respectively. Kang et al., Bilchik et al. and WHO.[15,16,17] also consider moderately differentiated tumors as the most common colorectal carcinomas, while comparing age of the patient with the histological subtype of colon carcinoma, it was seen that mean age of diagnosis of Adenocarcinoma NOS, Mucinous carcinoma and signet ring cell carcinoma was 55,48 , and 54.3 years respectively.

Proportion of young patients was highest for signet ring cell carcinoma followed by Mucinous and Adenocarcinoma, i.e. $33.3 \%, 29.6 \%$ and $18.3 \%$ respectively. Sasaki et al.[18] had given mean age of presentation for Adenocarcinoma NOS, Mucinous carcinoma and signet ring cell carcinoma as 61.5, 57.7 and 52 years respectively. Okuno et al.[19] stated that Mucinous carcinoma is more common in patients younger than 40 years of age as compared to the garden variety of Adenocarcinoma NOS. Sasaki et al.[20] compared Mucinous and signet ring cell carcinoma and found that the mean age of diagnosis of signet ring cell is lower than Mucinous and Adenocarcinoma NOS.

Gender proportion was analysed amongst different histological subtypes. We found that Male:Female ratio of Adenocarcinoma NOS, Mucinous carcinoma and signet ring cell carcinoma in our study was 1.8:1,2:1 and 2:1 respectively. Okuno et al.[19] stated that Mucinous carcinoma is more common in females. Also Sasaki et al.[18] had given Male:Female ratio for Mucinous carcinoma as 1.2:1. This discordance between literature and our study can be explained by regional variations in population and relatively lesser number of patients of Mucinous and signet ring cell carcinoma encountered in this study period.

On analysing lymphatic, vascular and perineural invasion, it was found that lymphatic invasion was seen in $51.5 \%$, vascular invasion in $14.5 \%$ and perineural invasion was present in $11.5 \%$ of all the cases. Sprett et al. and Torlakovic et al.[21,22] while comparing the proportions of patients having lymphatic, vascular and perineural invasion noted that lymphatic invasion was seen in maximum number of cases, whereas perineural invasion was present in minimum number of cases. With regard to tumor depth ( $\mathrm{T}$ stage) majority of the cases in this study presented as Stage T3 $(64.5 \%)$ followed by T4 $(25.5 \%)$. T1 and T2 constituted $2.5 \%$ and $7.5 \%$ respectively. When comparison of nodal stage was done amongst different histological subtypes, it was seen that N0 was the most common presentation in Adenocarcinoma NOS, whereas N2 was 1 commonest in Mucinous and signet ring cell carcinoma. Sasaki et al.[18] compared Mucinous, signet ring cell carcinoma with Adenocarcinoma NOS for various parameters. Majority of the cases of Adenocarcinoma NOS had reactive Hyperplasia of the lymph node while maximum number of cases of Mucinous carcinoma and signet ring cell carcinoma were associated with lymph node metastasis. Maksimović Sl.[23] concluded that only $4 \%$ cases of Adenocarcinoma NOS were associated with lymph node 
metastasis as compared to $12 \%$ and $11 \%$ cases of Mucinous and signet ring cell carcinoma respectively. Maksimović and Okuno et al.[19,23] studied and compared Mucinous carcinoma with Adenocarcinoma NOS in detail and concluded that lymph node metastasis is more common in Mucinous carcinoma. Symonds et al. studied 893 cases of colorectal carcinomas, out of which mucinous carcinoma comprised 132 cases and noted that $31 \%$ of mucinous carcinomas were associated with villous adenomas, implying a histogenetic relationship. Moreover, this finding again emphasizes the neoplastic potential of the villous adenoma, especially in the rectum where the development of mucinous carcinoma is particularly ominous.[24] Psathakis et al.[25] while comparing Adenocarcinoma NOS with signet ring cell carcinoma stated that higher proportion of the cases of later were associated with lymph node metastasis as compared to former. All these studies including our study suggested that Mucinous and signet ring carcinoma are more commonly associated with lymph node metastasis as compared to the garden variety of Adenocarcinoma NOS.

A solitary case of spindle cell carcinoma in the present study was having nodal stage of N2. Choi et al.[26] presented a case report of sarcomatoid carcinoma of colon along with its literature and highlighted its aggressiveness and higher incidence of nodal and distant metastasis. Metastasis was present in only $5.5 \%$ of all the cases in our study. Manfredi et al.[27] however studied the incidence of metastasis in colorectal carcinoma before they have undergone any surgical intervention and evaluated that $14.5 \%$ of the patients had metastasis at the time of diagnosis. Those patients who had evidence of extensive metastasis at the time of diagnosis may not have been considered for major surgery and hence were not included in the study. Different histological subtypes had different proportion of cases with metastasis, i.e. $4.7 \%$ cases of Adenocarcinoma NOS had evidence of metastasis whereas it was present in $11.1 \%$ cases of Mucinous carcinoma. Okuno et al. and Maksimović.[19,23] compared Adenocarcinoma NOS with Mucinous carcinoma and stated that $22 \%$ cases of mucinous were associated with metastasis as compared to just $4 \%$ of Adenocarcinoma NOS , findings similar to the present study.

Sites of metastasis of colorectal carcinoma which were encountered in the present study were omentum $(n=6)$, liver $(n=3)$, ileum $(n=1)$, ovary $(n=1)$. Sibio et al. ${ }^{[28]}$ analysed 859 cases of metastatic colorectal cancer and concluded that major sites of metastasis were liver (18\%), lung $(11.7 \%)$, distant lymph nodes $(12.7 \%)$ and peritoneum $(6.6 \%)$. Other less common sites of metastasis include Adrenals, Kidney, Bone, urinary bladder, ovaries, pleura, prostate, skin, spleen and Thyroid. Comparison of stage distribution in various studies is shown in Table IV.

The literature search also highlighted that either stage II or III predominated while Stage I and IV accounted for a lesser proportion of the cases which was similar to our study. ${ }^{[29,30,31,32]}$ (Table IV) While comparing stage distribution in various Histological subtypes, it was found that majority of the cases $(45 \%)$ of Adenocarcinoma NOS were of stage II whereas maximum number of cases of Mucinous and signet ring cell carcinoma were of stage III (55.6 and 100\% respectively). Sasaki et al.[18] compared staging in Mucinous and Signet ring cell carcinoma with Adenocarcinoma NOS and found that maximum number of cases (40\%) of Adenocarcinoma NOS were stage II, while majority of the cases of Mucinous and Signet ring cell carcinoma were1presented at higher stage, i.e. stage III (63\% and $91 \%$ respectively).
Similarly, Kang et al.[15] also commented on poor survival and advanced stage of presentation of Mucinous and signet ring cell carcinoma as compared to Adenocarcinoma NOS.

Correlating Age with stage in the present study, it was noticed that $10 \%$ of the younger patients (age <40years) presented at stage IV as compared to only $4.4 \%$ of the older subgroup. Fazeli et al.[32] correlated age group with stage and evaluated that the majority of younger patients $(<40$ years $)$ presented with stage III whereas maximum number of cases of $>40$ years of age were of stage II. Chiang et al.[33] evaluated that as the age increases, the tumor stage at diagnosis downgraded, tumor differentiation improved and mucin production increased, all favouring a better outcome. So in case of colorectal carcinoma, younger patients present at higher stage. The reason for this can be explained by greater delay in diagnosis in young patients leading to more advanced stages. Also as discussed earlier there is more incidence of signet and Mucinous carcinoma in younger patients and greater proportion of cases arising in ulcerative colitis comparing sex of the patient with stage of tumor it was seen that the maximum number of males presented with stage III, while stage II was predominant amongst females. Griffin et al. and Alipour et al.[34,35] studied various predictors of survival in colorectal cancer and evaluated that for a given age and stage, females had better outcome than males which was reflected in our study too.

When comparison was done with respect to site of the tumor and the corresponding stage it was analysed that the majority of the right sided tumors were having stage II (54.1\%) while left sided tumors were predominantly presented with stage III $(52.6 \%)$. Wu et al.[36] conducted a study to correlate tumor subsite with stage and stated that cancers on right side colon are more likely to be localized as compared to that on left side, i.e. right sided tumors are of lower stage as compared to left sided tumors. Russell et al.[37] evaluated that $13.9 \%$ of right sided colon were associated with metastasis as compared to $20.2 \%$ of left sided colon.

Grade of tumor was also correlated with its stage. Majority (80\%) of the well differentiated tumors were of stage II, whereas maximum proportions of moderately and poorly differentiated tumors were presented with stage III. Nabi et al.[14] gave description of grade with stage. They studied that majority of well and moderately differentiated tumors were of stage II, whereas maximum proportion of poorly differentiated tumors had stage III. Similarly Ueno et al., Nacopoulou et al. and Vasile et al.[13,38,39] also confirmed the poor survival of high-grade tumors. Spratt et al.[21] evaluated that survival of patients with colorectal carcinoma is related to lymphocytic response, as more the lymphocytic response better is the survival of patient. Also Nacopoulou et al.[38] stated that the patients with tumors associated with lymphocytic response at the advancing edges have better survival as compared to the tumors lacking it. So as the intensity of associated lymphocytic response increases, better will be its prognosis. Our analysis also had the same outcome. When associated lesions of the cases were analysed it was found that 5 cases were associated with ulcerative colitis and 19 were associated with polyp in the adjacent colon. There is an overwhelming evidence in the literature for a parallelism between adenomatous polyps and colonic carcinoma. Studies done by Bat et al., Clark et al. [40,41] have shown that populations that have a high incidence of polyps also have a high incidence of carcinomas and vice versa. 
MIB-1 was available for only 18 cases in the study. Out of which 15 were of stage II.

MIB 1 ranged from 2\%-85\%. We have been unable to demonstrate a correlation between MIB 1 labelling index with the stage of tumor. The lack of correlation may be explained by small sample size for MIB 1. Also most of the cases where MIB 1 was available were of stage II as in this stage, MIB 1 has a prognostic role. Tumors of stage II with high MIB 1 will be given adjuvant chemotherapy and will be better responding to it as compared to tumors having low MIB 1activity. The same conclusion was also drawn by a study of Shepherd et al.[42]

\section{CONLCUSION}

The incidence of colorectal carcinomas is increasing in Indian population. The pathologists and clinician must be aware of the behaviour of the cancer and various staging pattern, associated lesions and prognostic factors which can help in early diagnosis and treatment.

\section{REFERENCES}

1. American Cancer Society (ACS). Cancer facts and figures-1997. Atlanta (GA): ACS; 1997.

2. World Health Organization (WHO). The world health report. Geneva (Switzerland): WHO; 1997.

3. Mohandas KM. Colorectal cancer in India: controversies, enigmas and primary prevention. Indian J Gastroenterol 2011;30(1):3-6.

4. Amin TT, Suleman W, Taissan AA, Joher AL, Mulhim O, Yousef AH. Patients' Profile, Clinical Presentations and Histopathological Features of Colorectal Cancer in Al Hassan Region, Saudi Arabia. Asian Pacific J Cancer Prev 2012;13:211-6.

5. Krasna MJ, Flancbaum L, Cody RP, et al.: Vascular and neural invasion in colorectal carcinoma. Incidence and prognostic significance. Cancer 1988;61:1018-23.

6. Shepherd NA, Richman PI, England J. Ki-67 derived proliferative activity in colorectal adenocarcinoma with prognostic correlations. Journal of Pathology 1988;155:213-9.

7. Wu XC, Chen VW, Steele B, Ruiz B, Fulton J, Liu L, et al. Subsite specific incidence rate and stage of disease in colorectal cancer by race, gender and age group in the United States, 1992-1997. Cancer 2001;92(10):2547-54.

8. Gomez D, Dalal Z, Raw E, et al. Anatomical distribution of colorectal cancer over a 10 -year period in a district general hospital: is there a true "rightward shift?" Postgrad Med J 2004;80:667-9.

9. Ponz de Leon M, Marino M, Benatti P, Rossi G, Menigatti MI, Pedroni $M$, et al. Trend of incidence, subsite distribution and staging of colorectal neoplasms in the 15-year experience of a specialised cancer registry. Annals of Oncology 2004;15:940-6.

10. Yoshida T, Akagi Y, Kinugasa T, Shiratsuchi I, Ryu Y, Shirouzu K. Clinicopathological study on poorly differentiated adenocarcinoma of the colon. Kurume Medical Journal 2011;58:41-6.

11. Fenoglio L, Castagna E, Comino A, Luchino C, Senore C, Migliore E, et al. A shift from distal to proximal neoplasia in the colon: a decade of polyps and CRC in Italy. BMC Gastroenterology 2010;10:139-44.
12. Demers RY, Severson RK, Schottenfeld D, et al. Incidence of colorectal adenocarcinoma by Anatomic subsite. Cancer 1997;79:441-7.

13. Ueno $H$, Mochizuki $H$, Hashiguchi $Y$, Ishiguro M, Kajiwara Y, Sato T, et al. Histological grading of colorectal cancer: a simple and objective method. Ann Surg. 2008;247(5):811-8.

14. Nabi U, Nagi AH, Riaz S, et al. Morphological evaluation of colorectal carcinoma with grading staging and histological types. J Pak Med Assoc. December 2010;60(12):998-1001.

15. Kang H, O'Connell JB, Maggard MA, et al. A 10-year outcomes evaluation of mucinous and signet-ring cell carcinoma of the colon and rectum. Dis Colon Rectum 2005;48:1161-8.

16. Bilchik AJ, DiNome M, Saha S, Turner RR, Wiese D, McCarter M, et al. Prospective multicenter trial of staging adequacy in colon cancer. Arch Surg June 2006;141:52734.

17. Hamilton SR, Rubio CA, et al. editors. Carcinoma of the colon and rectum In: Hamilton SR and Aaltonem LA: World Health Organization Classification of Tumors. Pathology and Genetics of Tumors of the Digestive System. IARC Press; Lyon 2000;104-19.

18. Sasaki O, Atkin WS, Jass JR. Mucinous carcinoma of the rectum. Histopathology 1987;11:259-72.

19. Okuno M, Ikehara T, Nagayama M, Kato Y, Yui S, Umeyama K. Mucinous colorectal carcinoma: clinical pathology and prognosis. Am Surg 1988 Nov; 54(11):681-5.

20. Sasaki S, Masaki T, Umetani N, Futakawa N, Ando H, Muto T. Characteristics in primary signet-ring cell carcinoma of the colorectum, from clinicopathological observations. JPN J Clin OncoI 1998;28(3):202-26.

21. Spratt JS, Spjut HJ. Prevalence and prognosis of individual clinical and pathologic variables associated with colorectal carcinoma. Cancer 1967;20:1976-85.

22. Torlakovic E, Skovlund E, Snover DC, et al.: Morphologic reappraisal of serrated colorectal polyps. Am J Surg Pathol 2003;27:65-81.

23. Maksimović S. Survival rates of patients with mucinous adenocarcinoma of the colorectum. Med Arh 2007;61(1):26-9.

24. Symonds DA, Vickery AL. Mucinous carcinoma of the colon and rectum. Cancer 1976 Apr; 37(4):1891-900.

25. Psathakis D, Schiedeck TH, Krug F, Oevermann E, Kujath P, Bruch HP. Ordinary colorectal adenocarcinoma vs. primary colorectal signet-ring cell carcinoma: study matched for age, gender, grade, and stage. Dis Colon Rectum 1999 Dec; 42(12):1618-25.

26. Choi YY, Jeen YM, Kim YJ. Sarcomatoid carcinoma of colon: extremely poor prognosis. J Korean Surg Soc 2011;80:S26-30.

27. Manfredi S, Lepage C, Hatem C, Coatmeur O, Faivre J, Bouvier AM. Epidemiology and management of liver metastases from colorectal cancer. Ann Surg 2006;244:254-9.

28. Sibio GD, French SW. Metastatic Patterns of Cancers: Results from a Large Autopsy Study. Arch Pathol Lab Med. 2008;132:931-9. 
29. Fisher ER, Sass R, Palekar A, et al.: Dukes' classification revisited. Findings from the National Surgical Breast and Bowel Projects. Cancer 1989;64:2354-60.

30. O'Connell JB, Maggard MA, Ko CY. Colon cancer survival rates with the new American Joint Committee on cancer sixth edition staging. J Natl Cancer Inst 2004;96:1420-5.

31. Salminen E, Palmu S, Vahlberg $\mathrm{T}$, et al. Increased proliferative activity measured by immunoreactive Ki-67 is associated with survival improvement in recto/rectosigmoid cancer. World J Gastroenterol 2005;11:3245-9.

32. Fazeli MS, Adel MG, Lebaschi AH. Colorectal Carcinoma: a retrospective, descriptive study of age, gender, subsite, stage, and differentiation in Iran from 1995 to 2001 as observed in Tehran University. Dis Colon Rectum 2007;50:990-5.

33. Chiang JM, Chen MC, Changchien CR, Chen JS, Tang R, Wang JY, et al. Favourable influence of age on tumor characteristics of sporadic colorectal adenocarcinoma: patients 30 years of age or younger may be a distinct patient group. Dis Colon Rectum 2003;46(7):904-10.

34. Griffin MR, Bergstralh EJ, Coffey RJ, et al. Predictors of survival after curative resection of carcinoma of the colon and rectum. Cancer 1987;60:2318-24.

35. Alipour S, Kennecke HF, Lim HJ, et al. Gender differences in outcomes for early stage colon cancer. J Clin Oncol 2012;30(suppl 4; abstr 605).
36. Wu XC, Chen VW, Steele B, Ruiz B, Fulton J, Liu L, et al. Subsite specific incidence rate and stage of disease in colorectal cancer by race, gender and age group in the United States, 1992-1997. Cancer 2001;92(10):2547-54.

37. Russell AH, Tong D, Dawson LE, et al. Adenocarcinoma of the proximal colon sites of initial dissemination and patterns of recurrence following surgery alone. Cancer 1984;53:360-7.

38. Nacopoulou L, Azaris P, Papacharalampous N, et al. Prognostic significance of histologic host response in cancer of the large bowel. Cancer 1981;47:930-6.

39. Vasile L, Olaru A, Munteanu M, Pleşea IE, Şurlin V, Tudorașcu C. Prognosis of colorectal cancer: clinical, pathological and therapeutic correlation. Rom J Morphol Embryol 2012;53(2):383-91.

40. Bat L, Pines A, Ron E, Rosenblum Y, Niv Y, Shemesh E: Colorectal adenomatous polyps and carcinoma in Ashkenazi and non-Ashkenazi Jews in Israel. Cancer 1986;58:1167-71.41.

41. Clark JC, Collan Y, Eide TJ, Estève J, Ewen S, Gibbs NM, et al. Prevalence of polyps in an autopsy series from areas with varying incidence of large-bowel cancer. Int J Cancer 1985;36:179-86.

42. Shepherd NA, Richman PI, England J. Ki-67 derived proliferative activity in colorectal adenocarcinoma with prognostic correlations. Journal of Pathology 1988;155:213-9. 